\title{
La intervención grupal de índole orientadora: demandas de sentido y competencias para el ejercicio profesional
}

\section{Orientational Group intervention: sensory demands and professional performance competences}

\author{
Ana Victoria Garita Pulido \\ Egresada de la Maestría Profesional en Orientación \\ Universidad de Costa Rica \\ San José, Costa Rica \\ avictoria@gmail.com
}

Recibido: 13-III-2012 • Aceptado: 06-IX-2012 • Corregido: 26-XI-2012

\begin{abstract}
Resumen: Este artículo hace referencia a los aprendizajes obtenidos a partir de la reflexión sobre el trabajo realizado en una intervención orientadora, ejecutada de manera participativa con un grupo de hombres con VIH/Sida residentes en el Hogar Nuestra Señora de la Esperanza en Cartago, con la cual se buscaba obtener información acerca de su realidad y aportar a su bienestar emocional. Se hace alusión a los argumentos que dieron pie a dicha intervención, al posicionamiento epistemológico, teórico y metodológico asumido por la facilitadora y se presenta el prototipo de acción que se construye para tal fin. Se delimitan algunas demandas de sentido y se esbozan ciertas competencias necesarias para una intervención orientadora de tipo grupal, a la vez se abordan algunos elementos de la comunicación que resultan importantes para este tipo de intervención y se sugieren ciertos patrones de relación e interacción que deben evitarse para obtener los beneficios potenciales de procesos de dicha indole. Estos aspectos amplian los referentes teóricos y metodológicos para la intervención, lo cual constituye un insumo importante para la actualización profesional, de manera que se aporta a la Orientación como disciplina y profesión.
\end{abstract}

Palabras clave: Intervención, grupo, VIH/Sida,

\section{Introducción}

La experiencia de intervención a la cual alude este artículo es un proceso grupal ejecutado con un grupo de hombres con VIH/Sida residentes en el Hogar Nuestra Señora de la Esperanza en Cartago, que sirve como estrategia de recolección de información y de intervención desde la Orientación como parte del Trabajo Final de Investigación Aplicada para optar al grado de Maestría Profesional en Orientación.

El estado del arte evidencia una serie de argumentos que sustentan dicha intervención, entre estos, la necesidad de abordar a las personas que ya viven con el virus como parte de la respuesta social al VIH/Sida y a la vez la trascendencia de la dimensión emocional como arista 
orientación, competencias.

\begin{abstract}
This article makes reference to the knowledge obtained from the analysis of the results of a participative orientation intervention to a group of male HIV/ AIDS patients who reside in Hogar Nuestra Señora de la Esperanza in Cartago, through which we expect to find information about their reality, and support their emotional wellness. The arguments that motivated such intervention are presented, as well as the epistemological, theoretical and methodological positioning used by the facilitator; also, the prototype of action developed for such purpose. Some sensory demands are delimited, and certain necessary traits for a group orientation are sketched. At the same time, some communication elements that are important for this type of intervention are developed, and certain relation and interaction profiles that should be avoided to obtain such potential benefits are indicated. These elements support Orientation as a discipline and profession as they expand theoretical and methodological references for an intervention, which becomes an important input for professional updating.
\end{abstract}

Keywords: Intervention, group, HIV/AIDS, orientation, competences. en el tratamiento para propiciar su bienestar integral (Andrade y Araya, 2006; Brenes, 2006; Saravia y Matarrita, 2004; Benjamín, Gutiérrez y Ruiz, 1996; Cordero y González, 1996).

Además, es urgente abordar a los hombres en la adultez temprana e intermedia, por constatarse que son un grupo poblacional altamente afectado por el virus y por los riesgos que supone la masculinidad para su salud, asimismo por la invisibilización de que son objeto como sujetos de investigación e intervención a raíz de una percepción distorsionada de la perspectiva de género (ONUSIDA, 2010; Faur, 2004; Campos y Salas, 2002; Lagarde, 1997).

Por otro lado, la Orientación como disciplina cuenta con los referentes teóricos, técnicos y metodológicos para comprender y favorecer el desarrollo socioemocional de las personas en las diversas etapas del desarrollo, en los diferentes contextos y situaciones en que estas se encuentren. Ante las realidades de las personas que viven con VIH/Sida, y desde una perspectiva personal-social, se reconoce el compromiso social de la orientación por el aporte que brinda en el fortalecimiento de la salud mental. La intervención orientadora contribuye aportando conocimientos para la comprensión de esta realidad en procura del bienestar emocional y, por ende, físico y social de las personas participantes (Gavilán, 2006), que sirven de insumo para las acciones que emprenden diversas instituciones y organizaciones sociales que trabajan con la población que vive con el virus.

\section{La intervención: acerca del posicionamiento epistemológico, teórico y metodológico}

Las necesidades evidenciadas con el estado del arte motivaron a asumir una finalidad no tradicional para la intervención, más que ser educativo-didáctico el proceso fue de tipo orientador. De ahí que la intervención ejecutada se caracteriza 
por ser un proceso grupal que adquirió un carácter subjetivo y objetivo, personal y colectivo, dinámico y dialéctico, retroalimentado y participativo (Gutiérrez, 2002).

$\mathrm{El}$ posicionamiento epistemológico focaliza las experiencias tal y como las viven los participantes y los significados, percepciones y creencias en torno a ellas. Ubica al grupo como protagonista del proceso de reflexión, construcción y aplicación de conocimientos para su beneficio, lo que constituye un proceso activo de aprendizaje para la introspección y transformación dialéctica de su realidad (Gurdián, 2007; Guba 1978 citado en Martínez, 1999; Rodríguez, Gil y García, 1996; Vargas, 1991).

Uno de los propósitos del estudio es favorecer la salud de los participantes, esto lleva a fundamentar teóricamente el proceso de salud-enfermedad, los estilos de vida de los hombres y en particular de aquellos que viven con el VIH/Sida; así como la teoría de los procesos de evaluación cognitiva como un punto de partida para el afrontamiento de su realidad.

Con base en este posicionamiento teórico, la intervención operacionaliza una concepción contextual de la salud vinculada al análisis de factores políticos, económicos, sociales, ambientales, entre otros, para la comprensión de la responsabilidad personal frente al mantenimiento o mejoramiento de la salud, además de prestar atención a las evaluaciones cognitivas asociadas a su realidad personal como determinante para su afrontamiento (Marks, Murray y Evans, 2008; Flórez, 2007; Oblitas, 2006; Carmona, Rozo y Mogollón, 2005; OPS, 1996; Lazarus y Folkman, 1986).

De ahí que la intervención concibe como principal recurso a cada persona con sus experiencias, así como su capacidad de aprehender para la transformación o el mejoramiento de sus percepciones relacionadas con su experiencia de vida. Por tratarse de un grupo de hombres adultos que viven con VH/Sida, se consideran los principios de la andragogía, procesos educativos y de aprendizaje en la edad adulta.
Este proceso orientador privilegia el rol activo del grupo, la interacción entre los participantes y el respeto para compartir sus experiencias y necesidades con libertad y confianza. Aspectos necesarios para propiciar una reconstrucción de conocimientos aplicables a su propia realidad (Knowles, 1986 citado en De Natale, 2003). Así, el grupo constituye un espacio de contención y apoyo donde, con base en sus potencialidades, encuentran pautas para un cambio cognitivo y personal, conducente a un adecuado afrontamiento de la realidad personal (Ortiz, 1992 citado en Arrivillaga, Corea y Salazar, 2007).

Si bien es cierto existen diferentes modalidades de Orientación y de intervención, también es cierto que la formación profesional ha estado más enfocada en una modalidad que enfatiza un rol pedagógico educativo. Razón por la que este posicionamiento metodológico ubica a la orientadora-facilitadora en una intervención de tipo grupal y por ende asume un rol distinto a los conocidos y aprendidos durante su formación y experiencia profesional. Supuso retos y cuestionamientos ante experiencias diferentes que la llevan a nuevos aprendizajes para su praxis profesional. Lo anterior implica asumir un rol de carácter instrumental que le permitía distanciarse críticamente del grupo con el fin de catalizarlo para ayudarlo a avanzar en la consecución de sus propósitos (López, 1998; Manigot, s.f.).

Para tal fin se construye un prototipo de acción que le sirva de guía en el proceso orientador, que se basa en la articulación de dos enfoques de Orientación: la logoterapia y el afrontamiento para el abordaje del grupo participante. Ambos coinciden en la capacidad de las personas para desenvolverse en consecuencia con su potencial, aportan elementos importantes que favorecen la toma de conciencia de su realidad personal y permiten la deconstrucción y construcción de nuevos conocimientos después de separarse de su realidad para mirarla objetivamente y reflexionan sobre 
ella para afrontarla. Se les permite conducirse de acuerdo con sus capacidades e incidir positivamente en su bienestar personal (Frankl, 1994; Frankl, 1987; Lazarus y Folkman, 1986).

Con base en un acercamiento a los ejes centrales de dichos enfoques, se construye un proceso grupal que articula algunas de sus técnicas y estrategias e involucra tres momentos (Frankl, 1987, Frankl, 1984; Lazarus y Folkman, 1986; Frankl, 1978), de manera que para cada sesión se plantea la siguiente estructura:

a. Autoconciencia: Los participantes toman conciencia de sus experiencias personales, relacionadas con su estilo de vida y su afrontamiento. Se utiliza la técnica del diálogo socrático, técnica que posibilita un proceso de autoexploración que los lleve a inferir las demandas de sentido inherentes a estas.

b. Valoración de la realidad y extracción de las demandas de sentido que conlleva: Busca favorecer el autodistanciamiento de la realidad personal de manera que puedan mirarla con objetividad y se vea favorecida su respuesta emocional. Así se hace caso omiso a los síntomas relacionados y se pueden percibir los acontecimientos en su justa dimensión. Se utiliza la técnica del diálogo socrático y la derreflexión, y con ello se logra extraer las demandas de sentido inherentes con el fin de que salgan a enfrentarlas con una actitud adecuada.

c. Voluntad de sentido para afrontar el problema: A partir del autodistanciamiento y la valoración de sus situaciones como reto-compromiso, se exploran sus recursos personales, sociales y materiales para hacerle frente a su realidad. Se utiliza la técnica de la intención paradójica, con la que se pretende que se enfrenten por instantes a lo que temen, lo acepten anticipadamente e ironicen. Es así como se reduce el temor expectante y los síntomas, para asumir una actitud adecuada y esperanzadora ante su realidad. También se utilizan otras estrategias de afrontamiento dirigidas al problema.

\section{El grupo}

El grupo está constituido por diez hombres en la etapa de la adultez temprana e intermedia, quienes por la ausencia de redes sociales que les apoyen en el proceso de recuperación, a causa de una enfermedad oportunista propia del proceso de infección por VIH/ Sida, se encontraban institucionalizados en el Hogar Nuestra Señora de la Esperanza en Cartago. El tiempo de residencia en el Hogar oscila entre un mes y dos años, se abordan hombres solteros, casados y en unión libre, solo algunos de ellos con hijas e hijos. Al momento de realizar la investigación se encontraban desempleados.

\section{Las competencias necesarias para la intervención orientadora de tipo grupal}

El desarrollo de procesos grupales sustentados en las necesidades y características de una población particular trae implícita una serie de demandas de sentido vinculadas al ejercicio de un rol que adquiere un carácter dinámico y flexible, que permite tanto a las personas destinatarias de dichos procesos como a quien los facilita la creación y recreación en la ejecución conjunta. Este tipo de intervención supone deconstruir estructuras tanto en lo personal como en lo profesional, ya que implica una toma de postura diferente, caracterizada por el intercambio de roles y poderes con las personas destinatarias de estos procesos, que ubiquen a la persona 
facilitadora como catalizadora del grupo (López, 1998).

Es de relevancia compartir una serie de lecciones aprendidas con la intervención llevada a cabo, desde la cual surgen cuestionamientos que sirven de insumo para delimitar lo que, según lo aprendido, implica el desarrollo de una intervención grupal con una finalidad de tipo orientadora. Es a partir de la reflexión realizada sobre lo actuado que se delimitan a continuación algunas competencias identificadas como necesarias para la ejecución de dichos procesos grupales:

a. Apropiación del posicionamiento epistemológico: Se requiere conciencia de conocimiento del posicionamiento epistemológico que subyace en una intervención de tipo orientadora, y con base en la formación, conocimiento y experiencia profesional, los retos que supone en relación con la postura asumida. Esto demanda la valoración previa de los objetivos y las creencias profesionales acerca de lo que se pretende lograr con el proceso, del concepto de ser humano inherente, del papel que desempeñan tanto las personas participantes como la facilitadora. La omisión de dicha valoración puede dificultar la apropiación de un rol realmente facilitador que parta de la firme creencia en las capacidades de cada persona y del grupo como tal para que este asuma un rol protagónico en el proceso y con ello propiciarse su bienestar.

b. Comprensión del acontecer a lo interno de las personas que integran el grupo: Las necesidades particulares de las personas participantes toman relevancia en este tipo de intervención, constituyen tanto el punto de partida como el de llegada y guían las tácticas y técnicas de actuación de la persona facilitadora (Manigot, s.f.) ubicándola de esta forma en un rol no necesariamente directivo. La aplicación de estrategias y técnicas propias de los enfoques de orientación que fundamentan su trabajo queda supeditadas a lo que el grupo necesite en el aquí y ahora, y no a un guión o planeamiento previamente definido. Se otorga primacía a las necesidades del grupo en cuanto son las que marcan los derroteros y no una posición autoritaria-prescriptiva por parte de quien facilita el proceso. De ahí que resulta importante analizar al grupo previo a la intervención en relación con las características de las personas que lo integran como edad, sexo, nivel educativo, entre otros. Con base en ese análisis, se elabora un prototipo de acción ajustado a la etapa del desarrollo, a la realidad y necesidades de las personas participantes de manera que constituya un proceso activo de aprendizaje que disponga al grupo para la autogestión de su desarrollo.

c. Flexibilidad: Orientar implica trabajar con base en las necesidades del grupo y ajustar la intervención a sus características particulares, lo cual demanda de la persona facilitadora la valoración previa y en el proceso, de sus pautas de actuación y las estrategias o técnicas que requiere implementar para que el grupo avance en su desarrollo. Más que una planificación estructurada y rígida del proceso por ejecutar requiere un prototipo de acción flexible para atender sin limitar la espontaneidad del grupo para autodirigirse en la consecución de los objetivos. La claridad respecto a los presupuestos epistemológicos, teóricos y metodológicos de la persona facilitadora para sustentar la intervención favorece la toma de decisiones en relación con aquellos referentes que considere pertinente aplicar para atender de manera acertada lo que el grupo necesite en un momento determinado. 
d. Comprensión del acontecer grupal: Una demanda de sentido inherente a este tipo de procesos refiere a que la persona facilitadora logre trascender de la atención individualizada y contenida en el grupo hacia la atención y comprensión de lo grupal. Esto conlleva desarrollar habilidades eficaces para la intervención grupal, siendo fundamental e insustituible el vector comunicación, pues la valoración de los patrones de comunicación permite a la persona facilitadora obtener información relevante referida a la manera en que se relacionan las personas participantes, su capacidad para expresar intimidad, el intercambio de información y los significados que dan a su comunicación (Satir, 2002).

Por esta razón, los patrones de interacción y la claridad en la comunicación entre las personas que integran el grupo deben acentuarse, debido a que es "gracias a la comunicación que las personas pueden explicitar las necesidades y conocer las de los demás, lo que permite la agrupación para la consecución de un fin común” (Manigot, s.f.: 2).

El primer paso en la intervención es que la persona facilitadora tenga claridad conceptual con la diferenciación entre lo que es comunicación funcional y lo que es comunicación disfuncional. En la siguiente tabla se sintetizan los aspectos característicos de estos tipos de comunicación de acuerdo con Satir (2002):

Tabla 1

Tipos de comunicación

\begin{tabular}{|c|c|}
\hline Comunicación funcional & Comunicación disfuncional \\
\hline $\begin{array}{l}\text { Se declara o solicita algo de una mane- } \\
\text { ra clara y directa, la persona emisora y } \\
\text { receptora pueden aclarar lo que dicen y la } \\
\text { retroalimentación es posible. La intención y } \\
\text { el resultado de la comunicación concuerdan } \\
\text { y en caso contrario, es posible recurrir a la } \\
\text { aclaración. }\end{array}$ & $\begin{array}{l}\text { Las comunicaciones son indirectas, poco } \\
\text { claras y rara vez aclaradas. Al relatar una } \\
\text { experiencia emiten comentarios incomple- } \\
\text { tos, distorsionados o generalizados y se dan } \\
\text { sobreentendidos sin pedir aclaración. }\end{array}$ \\
\hline
\end{tabular}

Adaptado de Satir (2002)

En las interacciones, en aspectos vinculados a la formación de un código común dentro del grupo, en la claridad de los mensajes y las secuencias comunicacionales, se hace necesario intervenir. Ante una comunicación disfuncional es preciso devolverle al grupo las transacciones incompletas, indirectas o poco explícitas, verificar que los mensajes sean comprendidos por todas las personas que integran el grupo, explicitar las quejas o pedidos encubiertos, señalar los mensajes contradictorios, estimular la metacomunicación (el pedir y dar aclaraciones), explorar y cuestionar los desacuerdos entre miembros, hacer consciente la no atención a las respuestas de las demás personas del grupo, evidenciar sobreentendidos y hacer propuestas al grupo para que llegue a definiciones compartidas. Otro aspecto a prestar atención es a las secuencias comunicacionales; es decir, a la dirección de la comunicación y al grado de participación de quienes integran el grupo. Se requiere detectar roles, monopolios, alianzas y coaliciones con el fin de que la facilitadora promueva debilitarlos, 
si el grupo desde sus roles no lo hace, en aras de lograr una comunicación enriquecedora entre todas las personas participantes. Como proceso activo de aprendizaje, requiere que la persona facilitadora reconozca, enfatice y haga circular la síntesis o producto grupal entre sus integrantes de manera que se promueva su incorporación (Manigot, s.f.).

e. Voluntad crítica para la trascendencia personal y profesional: Una planificación flexible demanda de la persona facilitadora una capacidad crítica no solo para leer e interpretar lo que ocurre en las personas participantes y en el grupo, sino también hacer lectura o análisis crítico de lo que ocurre consigo misma. Ejercitar su rol con conciencia le permitirá extraer y asumir las demandas de sentido personales y profesionales implícitas en aquello que acontece y así embarcarse en un proceso de autoafrontamiento que facilite el reubicarse personal y epistemológicamente para atender de manera acertada el tipo de orientación y proceso que ejecuta. Ser capaz de realizar reflexión y análisis para trascenderse a sí misma, a sus experiencias previas, a su formación, a la incertidumbre que podría suponerle el intercambio de roles y poderes, le dispone cognitiva, emocional y conductualmente para ser consecuente con las demandas de sentido propias de ser profesional, de la disciplina y área en que se trabaja y de intervenir en estos procesos.

\section{Patrones de comunicación que deben evitarse en la intervención grupal}

Como parte de las lecciones aprendidas a partir de la reflexión sobre lo actuado, se reconoce que la comunicación cobra relevancia en la Orientación y por ende en la intervención grupal. Esto demanda en la persona facilitadora el conocimiento o la destreza necesaria para evitar patrones de relación e interacción disfuncionales en el grupo que pueden ser un obstáculo en la consecución de los objetivos. Se sugieren ciertos patrones de relación e interacción que deben evitarse al facilitar este tipo de procesos de acuerdo con Manigot (s.f.):

a) cuando todas las personas participantes se dirijan a una sola persona,

b) cuando una persona hable por todas las demás,

c) se presenten monólogos o diálogos que ubican en un rol pasivo al resto del grupo,

d) se emitan mensajes simultáneos y desordenados o que queden secuencias cortadas o interrumpidas que dejen relaciones o temas abiertos sin resolución.

Se debe involucrar en la discusión grupal a todas las personas participantes y respetar el espacio de cada quien para expresarse con libertad, así se logra una participación equitativa y que el grupo en su totalidad pueda recibir contención y apoyo.

La falta de experiencia de la facilitadora para intervenir en el acontecer grupal constituye una dificultad en el proceso ejecutado. Algunos de los patrones antes indicados se detectaron oportunamente ya avanzado el proceso.

La Orientación grupal requiere conocimiento científico en comunicación y roles, con lo cual se facilita que el grupo avance en la consecución de los objetivos propuestos y no se limite la obtención de los beneficios potenciales de este tipo de procesos.

\section{Consideraciones finales}

Los procesos grupales de índole orientador al estar centrados en las necesidades 
del grupo demandan una estructura que sea flexible y de menos dirección. La aplicación de los presupuestos teóricos-metodológicos y de las técnicas seleccionadas se realiza en función de los propósitos que se definan con antelación y lo que el grupo vaya requiriendo, no como parte de un guión inflexible previamente establecido.

Para la persona facilitadora, en algunos casos, trae implícito un proceso de acomodación entre su formación profesional, experiencias previas, sus supuestos y expectativas, la apropiación del posicionamiento epistemológico que sustenta su accionar y las circunstancias que intervienen en la ejecución.

Se requiere congruencia en la conducción del grupo desde los presupuestos teóricos, metodológicos, el enfoque de orientación con las técnicas propias y que sustentan el proceso. De ahí la necesidad de tener aptitudes que favorezcan un desempeño competente para hacer lectura comprensiva o interpretativa de lo que ocurre en cada uno de sus miembros e intervenir en el acontecer grupal.

Facilitar procesos grupales y de este tipo conlleva asumir las fortalezas y las debilidades así como las demandas de sentido implícitas. Aunque se experimenten limitaciones y dificultades la constante autoevaluación de lo que acontece durante la ejecución tanto en el grupo como en la facilitadora permite llevar a cabo acciones para hacer un adecuado manejo de ellas, transformándolas en fortalezas personales, situacionales y profesionales, para así lograr atender los propósitos planteados y obtener los resultados que se buscan.

\section{Referencias}

Andrade, L. \& Araya, J. (2006). Implicaciones personales y sociofamiliares del VIH/SIDA según la percepción de las mujeres seropositivas usuarias de la clínica del sida del hospital Monseñor Sanabria de Puntarenas: localidades de Puntarenas, Monteverde y Nicoya. (Tesis de licenciatura sin publicar). Universidad de Costa Rica.

Arrivillaga, M.; Correa, D. \& Salazar, I. (2007). Psicología de la Salud: abordaje integral de la enfermedad crónica. Colombia: Manual Moderno. Benjamín, J.; Gutiérrez, F. \& Ruiz, R. (1996). Implicaciones psicosociales del SIDA en la familia: un estudio cualitativo de casos. (Tesis de licenciatura sin publicar). Universidad de Costa Rica.

Brenes, M. (2006). Propuesta de intervención de enfermería en salud mental a las personas que viven con el VIH/ SIDA. Hospital México. (Tesis de maestría sin publicar). Universidad de Costa Rica.

Campos, A. \& Salas, J. M. (2002). "Aspectos teóricos y conceptuales acerca de la masculinidad”. En Masculinidades en Centroamérica. Costa Rica: Lara Segura editores.

Carmona, L.; Rozo, C. \& Mogollón, A. (2005). "La salud y la promoción de la salud: una aproximación a su desarrollo histórico y social”. En Revista Ciencias de la Salud. Vol. 3(1), Pp. 62-77

Cordero, L. \& González, S. (1996). Orientación integral para el mejoramiento de la calidad de vida para personas con SIDA. (Tesis de licenciatura sin publicar). Universidad Nacional.

De Natale, M. L. (2003). La edad adulta: una nueva etapa para educarse. España: Narcea.

Faur, E. (2004). Masculinidades y desarrollo social: las relaciones de género desde las perspectivas de los hombres. Colombia: Arango Editores.

Flórez, L. (2007). Psicología social de la salud. Colombia: Editorial El Manual Moderno.

Frankl, V. (1978). Psicoanálisis y existencialismo: de la psicoterapia a 
la logoterapia. México: Fondo de Cultura Económica.

Frankl, V. (1984). El hombre doliente. México: Fondo de Cultura Económica.

Frankl, V. (1987). Logoterapia y análisis existencial. España: Herder.

Frankl, V. (1994). La voluntad de sentido: conferencias escogidas sobre logoterapia. España: Herder.

Gavilán, M. (2006). "La formación de orientadores en contextos complejos con especial referencia a Latinoamérica". En Antología del curso Orientación para la vida adulta. Maestría Profesional en Orientación, Universidad de Costa Rica.

Gurdián, A. (2007). Paradigma cualitativo en la investigación socioeducativa. Costa Rica: Print Center.

Gutiérrez, J. (2002). "Educación popular y masculinidad". En Masculinidades en Centroamérica. Costa Rica: Lara Segura editores.

Lagarde, M. (1997). Género y feminismo. España: Horas y horas editorial.

Lazarus, R. y Folkman, S. (1986). Estrés $y$ procesos cognitivos. España: Ediciones Martínz Roca S.A.

López, P. (1998). Un método para la investigación acción participativa. España: Editorial Popular.

Manigot, M. (s.f.). "Intervenciones desde el vector comunicación". Material mimeografiado. En Antología del curso Orientación para la Vida Adulta, Maestría Profesional en Orientación. Universidad de Costa Rica.

Marks, D.; Murray, M. \& Evans, B. (2008). Psicología de la salud: teoría, inves- tigación y práctica. México: Editorial El Manual Moderno.

Martínez, M. (1999). Comportamiento Humano. México: Trillas.

Oblitas, L. (2006). Psicología de la salud $y$ calidad de vida. México: Thomson Learning

Programa Conjunto de las Naciones Unidas sobre VIH/SIDA [ONUSIDA] (2010). Global Report: UNAIDS report on the global AIDS epidemic 2010. Recuperado de http://data.unaids. org/pub/Report/2010/2010_epidemic_update_en.pdf

Organización Panamericana de la Salud [OPS] (1996). Promoción de la salud: una antología. Estados Unidos. Editorial Mc Graw Hill.

Rodríguez, G.; Gil, J. \& García, E. (1996). Metodología de la investigación cualitativa. Ediciones Aljibe.

Saravia, M. \& Matarrita, N. (2004). Algunos efectos emocionales que se dan como respuesta psicológica ante la posibilidad de muerte, experimentados por los miembros de dos familias con un niño que vive con VIH por vía vertical, entre los 4 y 5 años, del área metropolitana: un estudio exploratorio. (Tesis de licenciatura sin publicar). Universidad Católica de Costa Rica.

Satir, V. (2002). Terapia familiar paso a paso. México: Editorial Pax.

Vargas, Z. R. (1991). "La investigación participativa: cómo utilizarla en Orientación”. En Revista Educación. Vol. 15 (2), pp.103-130. Universidad de Costa Rica. 